\title{
Livedo Reticularis in a Patient with EBV Mononucleosis
}

\author{
Gorica Svalina1,2, Sean Ochsenbein ${ }^{1,2}$, J. Kelly Smith1,2* \\ ${ }^{1}$ Department of Academic Affairs, James H. Quillen College of Medicine, East Tennessee State University, \\ Johnson City, USA \\ ${ }^{2}$ Department of Biomedical Sciences, James H. Quillen College of Medicine, East Tennessee State University, \\ Johnson City, USA \\ Email: "smithj@etsu.edu
}

Received 7 January 2016; accepted 12 February 2016; published 15 February 2016

Copyright (C) 2016 by authors and Scientific Research Publishing Inc.

This work is licensed under the Creative Commons Attribution International License (CC BY).

http://creativecommons.org/licenses/by/4.0/

(c) (i) Open Access

\section{Abstract}

A 23-year-old woman with serologically confirmed EBV mononucleosis presented with fever, exudative pharyngitis, periorbital and lid edema, cervical lymphadenopathy, and splenomegaly. Two weeks after the onset of symptoms she developed a generalized symmetrical reticular eruption of unbroken hexagons characteristic of livedo reticularis that resolved over several weeks as her condition improved. To our knowledge, this is the first reported case of livedo reticularis to occur in a patient with EBV mononucleosis.

\section{Keywords}

Infectious Mononucleosis, EBV, Livedo Reticularis, Reticulate Eruption

\section{Introduction}

The mucocutaneous manifestations of mononucleosis due to infection with the Epstein-Barr virus (EBV) are protean, and include exudative tonsillitis, palatal petechiae, hairy leukoplakia, maculopapular rashes, urticaria, erythema multiforme, erythema nodosum, the Papular-Purpuric Gloves-and-Socks syndrome, periorbital and lid edema, and, rarely, genital ulcers [1]-[7].

We noted the occurrence of a generalized, symmetrical reticulate eruption characteristic of livedo reticularis in a patient with EBV mononucleosis. Although this reticulate eruption has been described to occur in association with parvovirus B19 and hepatitis C infections [8] [9], to our knowledge it has not previously been reported to occur in association with EBV.

${ }^{*}$ Corresponding author. 


\section{Case Report}

The patient, a 23-year-old previously healthy woman, presented with a chief complaint of throat pain and fatigue of three weeks duration. Her illness began with the abrupt onset of fever and chills which resolved within several days. Later that week she developed a sore throat, bilateral cervical adenopathy, swelling of her eyelids, intermittent discomfort in her splenic area, and profound fatigue. Two weeks after the resolution of her fever, she noted the onset of a "rash" on her trunk and extremities unrelated to exposure to cold. Her past medical history, family history, and review of systems was unremarkable. She was on no medications.

Physical examination revealed normal vital signs, bilateral periorbital and lid edema, bilateral cervical adenopathy, an exudative pharyngitis, and a palpable spleen. She had a symmetrical reticulate eruption of bluish hexagons involving her extremities and trunk that blanched with pressure and did not resolve with the application of heat-findings diagnostic of a secondary form of livedo reticularis (Figure 1).

A complete blood count revealed a relative and absolute lymphocytosis $(68.7 \%$ and 7600 lymphocytes/ $\mu \mathrm{L}$, respectively). Atypical lymphocytes (Downey cells) were noted in the peripheral blood smear. The complete blood count was otherwise normal. EBV serology revealed elevated levels of IgM and IgG antibodies to viral capsid antigen (>159.9 U/mL and $84.8 \mathrm{U} / \mathrm{mL}$, respectively), and undetectable antibodies to nuclear antigen, findings diagnostic of acute EBV infection. Blood tests for cryoglobulins and cold agglutinins, done because of her reticulate eruption, were negative.

The patient was treated conservatively with rest and steps to avoid splenic trauma. Her livedo reticularis resolved over several weeks as she improved clinically.

\section{Discussion}

Reticulate eruptions are one of the most important dermatologic signs of a physiological or pathological process involving the superficial vascular networks of the skin and subcutaneous tissue [10]. Disease affecting these networks can present with a range of eruptions, including livedo reticularis, livedo racemosa, reticular purpura and stellate necrosis [8]-[11].

Livedo reticularis is characterized by the appearance of a reticulate pattern of unbroken bluish hexagons in the superficial vascular networks of the skin and subcutaneous tissues; it can be primary (physiologic) or secondary
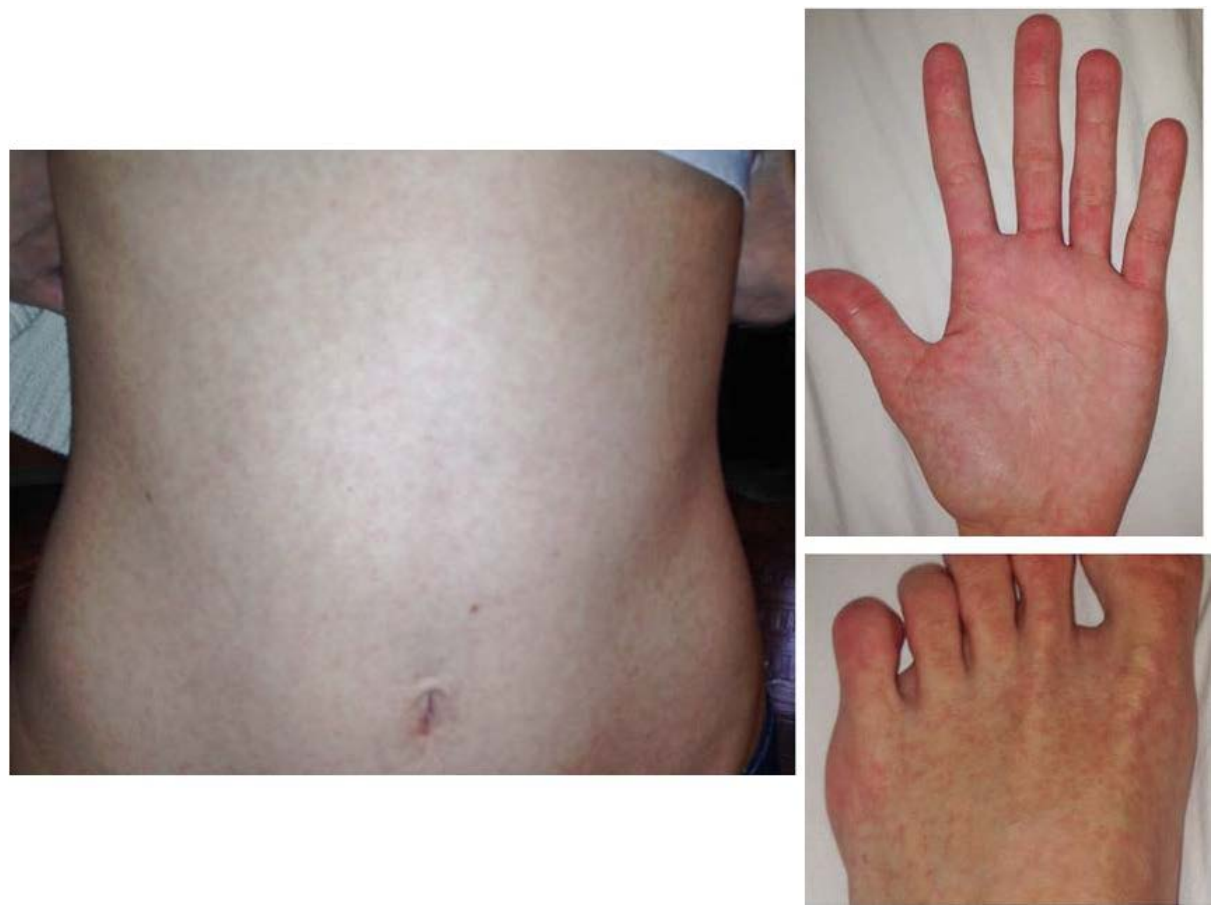

Figure 1. This symmetrical reticular eruption of bluish unbroken hexagons is characteristic of livedo reticularis. 
(pathologic). The primary eruption is commonly seen in infants and young women exposed to a cold environment, where it is often referred to as cutis marmorata; it is attributed to spasm of the central arteriole that feeds the hexagonally arranged outer veins of the angiosome, and it dissipates on warming [10] [11]. Secondary causes of livedo reticularis include drugs (such as amantadine), cryoglobulins, cold agglutinins, hyperviscosity syndromes, the antiphospholipid antibody syndrome, small and medium vessel vasculitis, emboli, calciphylaxis, connective tissue disorders, and, as mentioned, infections [8]-[11]. This reticulate pattern has been attributed to sludging of blood in the subpapillary microvascular plexus, but the exact mechanism is frequently unknown [11].

Livedo reticularis must be distinguished from livedo racemosa, which appears as an asymmetric irregular broken reticulate eruption that does not blanch or only partially blanches with pressure and never reverses with warming. This reticulate eruption is caused by a non-uniform and focal involvement of a limited number of vessels in the subpapillary vascular network and always signifies a pathological process including those described to occur in association with secondary forms of livedo reticularis [11].

The prognosis in primary forms of livedo reticularis is excellent. The prognosis in secondary forms of livedo reticularis and in livedo racemosa is less favorable and parallels that of the associated disease. All patients with primary and secondary forms of livedo should be encouraged to avoid cold environments, smoking, and the use of vasoconstricting medications [11].

\section{Conclusion}

EBV can be added to the list of viruses capable of producing a secondary form of livedo reticularis. If the infection is unassociated with the production of cold agglutinins or cryoglobulins, the livedo can be managed conservatively with rest and the avoidance of exposure to cold and the use of vasoconstrictors.

\section{Approval}

The patient gave written permission to publish this case report.

\section{References}

[1] Mendoza, N., Diamantis, M., Arora, A., Bartlett, B., Gewitzman, A., Tremaine, A.M., et al. (2008) Mucocutaneous Manifestations of Epstein-Barr Virus Infection. American Journal of Clinical Dermatology, 9, 295-305. http://dx.doi.org/10.2165/00128071-200809050-00003

[2] Wu, L.Y., Mesko, J.W. and Peterson, B.R. (1983) Cold Urticaria Associated with Infectious Mononucleosis. Annals of Allergy, 50, 271-274.

[3] Zawar, V., Chuh, A. and Sankalecha, S. (2009) Erythema Multiforme-Like Lesions in the Course of Infectious Mononucleosis. Journal of Dermatological Case Reports, 3, 44-46. http://dx.doi.org/10.3315/jdcr.2009.1035

[4] Llorens-Terol, J. and Martinez-Roig, A. (1983) Erythema Nodosum Associated with Infectious Mononucleosis. Helvetica Paediatrica Acta, 38, 91-94.

[5] Barnes, C.J., Alio, A.B., Cunningham, B.B. and Friedlander, S.F. (2007) Epstein-Barr Virus-Associated Genital Ulcers: An Under-Recognized Disorder. Pediatric Dermatology, 24, 130-134. http://dx.doi.org/10.1111/j.1525-1470.2007.00358.x

[6] Hsieh, M.Y. and Huang, P.H. (2004) The Juvenile Variant of Papular-Purpuric Gloves and Socks Syndrome and Its Association with Viral Infections. British Journal of Dermatology, 151, 201-206. http://dx.doi.org/10.1111/j.1365-2133.2004.05946.x

[7] Decker, G.R., Berberian, B.J. and Sulica, V.I. (1991) Periorbital and Eyelid Edema: The Initial Manifestations of Acute Infectious Mononucleosis. Cutis, 47, 323-324.

[8] Gibbs, M.B., English III, J.C. and Zirwas, M.J. (2005) Livedo Reticularis: An Update. Journal of the American Academy of Dermatology, 52, 1009-1019. http://dx.doi.org/10.1016/j.jaad.2004.11.051

[9] Dean, S.M. (2011) Livedo Reticularis and Related Disorders. Current Treatment Options in Cardiovascular Medicine, 13, 179-191. http://dx.doi.org/10.1007/s11936-011-0115-z

[10] Parsi, K., Partsch, H., Rabe, E. and Ramelet, A.A. (2011) Reticulate Eruptions. Part 1: Vascular Networks and Physiology. Australasian Journal of Dermatology, 52, 159-166. http://dx.doi.org/10.1111/j.1440-0960.2011.00749.x

[11] Parsi, K., Partsch, H., Rabe, E. and Ramelet, A.A. (2011) Reticulate Eruptions. Part 2: Historical Perspectives, Morphology, Terminology and Classification. Australasian Journal of Dermatology, 52, 237-244.

http://dx.doi.org/10.1111/j.1440-0960.2011.00819.x 


\section{Abbreviations}

EBV, Epstein-Barr virus;

$\mu \mathrm{L}$, microliters;

$\mathrm{U} / \mathrm{mL}$, units per milliliter. 